\title{
Impact of circulating vaspin levels on metabolic variables in elderly twins
}

\author{
K. Hida $\cdot$ P. Poulsen $\cdot$ S. Teshigawara $\cdot$ E. Nilsson $\cdot$ \\ M. Friedrichsen • R. Ribel-Madsen • L. Grunnet • \\ S. S. Lund $\cdot$ J. Wada $\cdot$ A. Vaag
}

Received: 2 August 2011 / Accepted: 26 October 2011 /Published online: 25 November 2011

(C) Springer-Verlag 2011

Keywords Adipokine · Insulin resistance - Twin study . Vaspin

To the Editor: We previously identified vaspin and demonstrated that vaspin mRNA is exclusively expressed in the visceral white adipose tissue of Otsuka Long-Evans Tokushima Fatty rats [1], and that injection of recombinant

Electronic supplementary material The online version of this article (doi:10.1007/s00125-011-2385-0) contains peer-reviewed but unedited supplementary material, which is available to authorised users.

\footnotetext{
K. Hida $\cdot$ E. Nilsson $\cdot$ M. Friedrichsen $\cdot$ R. Ribel-Madsen •

L. Grunnet $\cdot$ S. S. Lund $\cdot$ A. Vaag

Steno Diabetes Center,

Niels Steensens Vej1,

2820 Gentofte, Denmark

K. Hida $(\triangle)$

Department of Diabetology and Metabolism, National Hospital

Organization, Okayama Medical Center,

1711-1 Tamasu,

Kita-ku, Okayama 701-1192, Japan

e-mail: kzhi@okayama3.hosp.go.jp

P. Poulsen

Novo Nordisk A/S,

Soeborg, Denmark

Springer
}

\begin{tabular}{ll}
\multicolumn{2}{l}{ Abbreviations } \\
DZ & Dizygotic \\
$\mathrm{h}^{2}$ & Heritability \\
IFG & Impaired fasting glucose \\
IGT & Impaired glucose tolerance \\
MZ & Monozygotic \\
NGT & Normal glucose tolerance
\end{tabular}

vaspin into obese mice improved insulin sensitivity [2]. However, in humans the association between serum vaspin levels and obesity variables is conflicting [3, 4], and the relationship between circulating vaspin levels and glucose metabolism remains controversial $[5,6]$. In addition to these issues, it is still unknown whether serum vaspin levels are influenced by genetic or environmental factors. We therefore investigated the association of human serum vaspin levels with various anthropometric and clinical factors and elucidated the relative impact of genetic and environmental factors.

Participants were identified through the Danish Twin Register as previously described [7]. A total of 298 elderly twins (126 monozygotic [MZ]: 49 pairs and 28 single twins aged 63-83 years; 172 dizygotic [DZ]: 56 pairs and 60 single twins aged $62-83$ years) were enrolled in the study. All participants provided their written informed consent.

\footnotetext{
S. Teshigawara $\cdot$ J. Wada $(\bowtie)$

Department of Medicine and Clinical Science, Okayama

University Graduate School of Medicine, Dentistry and

Pharmaceutical Sciences,

2-5-1 Shikata-cho,

Kita-ku, Okayama 700-8558, Japan

e-mail: junwada@md.okayama-u.ac.jp

A. Vaag

Department of Clinical Sciences, Lund University, University

Hospital MAS,

Malmö, Sweden

M. Friedrichsen · A. Vaag

Department of Diabetes and Metabolism, Rigshospitalet,

Copenhagen, Denmark
} 
All procedures were performed according to the Declaration of Helsinki and approved by the regional Scientific Ethical Committees. We assessed serum vaspin concentrations employing RIA (Millipore, St Charles, MI, USA). Blood samples were obtained after an overnight fast in 295 participants. Insulin resistance was estimated by HOMA and calculated as [fasting plasma glucose $\left(\mathrm{Glc}_{0}\right)(\mathrm{mmol} / \mathrm{l}) \times$ (insulin $\left.\left.\left(\operatorname{Ins}_{0}\right)(\mathrm{pmol} / \mathrm{l}) / 6.95\right) / 22.5\right]$. According to the 1998 WHO criteria for a $75 \mathrm{~g}$ OGTT, we stratified the 295 twin participants into normal glucose tolerance (NGT, $n=151$ ), impaired fasting glucose or impaired glucose tolerance (IFG/ IGT, $n=18 / 75$, respectively), and type 2 diabetes $(n=51)$ groups.

Serum vaspin levels ranged from 0.01 to $3.68 \mathrm{ng} / \mathrm{ml}$ in all but four participants. One MZ twin pair and two DZ twins from different twin pairs displayed much higher levels ranging between 17.8 and $29.2 \mathrm{ng} / \mathrm{ml}$ compared with a mean level of $0.47 \mathrm{ng} / \mathrm{ml}$ in the remaining twins. The vaspin concentrations in the two MZ participants were 27.2 and $29.0 \mathrm{ng} / \mathrm{ml}$. The two DZ participants displayed vaspin levels of 17.8 and $29.2 \mathrm{ng} / \mathrm{ml}$, whereas their co-twins displayed much lower levels of 0.84 and $0.81 \mathrm{ng} / \mathrm{ml}$, respectively. We classified participants into two subgroups based on their serum vaspin levels (subgroup A: serum vaspin levels $<3.68 \mathrm{ng} / \mathrm{ml}$, and subgroup B: serum vaspin levels $>3.68 \mathrm{ng} / \mathrm{ml}$ ). No significant differences in clinical variables, other than WHR, were observed between the subgroups (see electronic supplementary material [ESM] Table 1). Similarly, we found no significant differences in clinical variables between the two DZ twins with high levels compared with their low level co-twins (ESM Table 2). We speculated that the higher vaspin levels are due to genetic rather than environmental factors. Henceforth, all of the statistical analyses in the present study were performed in subgroup A, unless otherwise indicated.

In the comparison of vaspin levels between the groups with various glucose tolerance statuses, we adjusted for the following confounders: twin pair relationship, zygosity, age, sex and BMI. Log transformed serum vaspin levels $\left(\log _{e}\right.$ vaspin) were significantly higher in participants with IFG/IGT and type 2 diabetes compared with participants with NGT (ESM Fig. 1). Stepwise regression analyses were performed, including independent variables such as zygosity, sex, age, BP and anthropometric indices as well as measures of glucose and lipid metabolism, to predict serum vaspin concentrations. Only age, zygosity, and triacylglycerol and fasting glucose levels were independently associated with serum vaspin concentrations (Table 1). No significant associations were detected between serum vaspin levels and sex, anthropometric indices, $\mathrm{HbA}_{1 \mathrm{c}}$, HOMA or BP.

Correlations of intra-twin pair phenotypic differences allow for elimination of the influence of common environ-
Table 1 Identification of factors influencing serum vaspin levels using stepwise regression analyses based on backward elimination

\begin{tabular}{llr}
\hline $\begin{array}{l}\text { Independent } \\
\text { variables }\end{array}$ & $\begin{array}{l}\text { Change in serum } \\
\text { vaspin levels (\%) }\end{array}$ & $p$ value \\
\hline Model 1 & & \\
Age & $4.9 \uparrow$ & $<0.0001$ \\
Zygosity & MZ $31.1 \uparrow$ vs DZ & 0.0351 \\
TG & $20.4 \downarrow$ & 0.0077 \\
Glc ${ }_{0}$ & $8.4 \uparrow$ & 0.0284 \\
Model 2 & & \\
Age & $5.0 \uparrow$ & $<0.0001$ \\
Zygosity & MZ $29.0 \uparrow$ vs DZ & 0.0476 \\
TG & $20.0 \downarrow$ & 0.0114 \\
$\mathrm{HbA}_{1 \mathrm{c}}$ & $11.0 \uparrow$ & 0.0993 \\
\hline
\end{tabular}

Arrows indicate an increase or decrease

The significance level for variable elimination was set at $p>0.05$

$\mathrm{Glc}_{0}$, fasting plasma glucose; TG, triacylglycerol

mental and maternal effects and, in particular, of the influence of genotype in MZ twins. We found no significant correlations between absolute vaspin levels and anthropometric variables, including WHR and BMI, in either MZ or DZ twins. However, we demonstrated a significant positive intra-twin pair correlation between serum vaspin levels and WHR in MZ twins $(r=0.306, p=0.018)$, but not in DZ twins (ESM Table 3), indicating that an increased degree of abdominal fat is associated with elevated serum vaspin levels, independent of any genetic component or of nongenetic factors, including maternal status, intrauterine conditions and age.

The heritability $\left(\mathrm{h}^{2}\right)$, which expresses the proportion of a trait's total variation attributable to genetic variation, is estimated to be twice the difference between the intraclass correlation of $\mathrm{MZ}$ and $\mathrm{DZ}$ twins $\left[\mathrm{h}^{2}=2\left(\mathrm{r}_{\mathrm{MZ}}-\mathrm{r}_{\mathrm{DZ}}\right)\right]$. The intraclass correlations for serum vaspin levels were not different between $\mathrm{MZ}$ and $\mathrm{DZ}$ twins $\left(r_{\mathrm{MZ}}=0.53 ; r_{\mathrm{DZ}}=0.33\right)$, and the $\mathrm{h}^{2}$ was 0.40 . When the intraclass correlations for vaspin levels were analysed separately by sex, the correlations in men were similar in $\mathrm{MZ}$ and $\mathrm{DZ}$ twin pairs $\left(r_{\mathrm{MZ}}=\right.$ $\left.0.42 ; r_{\mathrm{DZ}}=0.43\right)$, corresponding to an $\mathrm{h}^{2}$ of zero. This suggests an exclusively non-genetic contribution to the variation in serum vaspin levels. However, in women, the intraclass correlation was higher in $\mathrm{MZ}$ than $\mathrm{DZ}$ twin pairs $\left(r_{\mathrm{MZ}}=0.64 ; r_{\mathrm{DZ}}=0.25\right)$. The $\mathrm{h}^{2}$ of 0.78 suggests a major influence of genetic factors in women and thus sexual dimorphism in the heritability of serum vaspin levels. Interestingly, a sex difference in circulating vaspin levels was also found in previous studies, reporting elevated vaspin concentrations in female compared with male participants $[3,4]$. 
In conclusion, our results indicate that, in vivo, serum vaspin levels are elevated in individuals with IFG/IGT and type 2 diabetes. Vaspin levels did not correlate with HOMA or insulin levels; however, they correlated with fasting plasma glucose, suggesting a role in glucose metabolism, particularly in the fasting state. Finally, we demonstrated a non-genetic association between WHR and serum vaspin levels, and a higher $\mathrm{h}^{2}$ estimate for serum vaspin levels in women compared with men.

Acknowledgements The study was supported by grants from the Danish Diabetes Association, the Danish Strategic Research Council, the Danish Medical Research Council, EXGENESIS, Grant-in-Aid for Scientific Research (B) (23390241), Challenging Exploratory Research (23659470), Grant-in-Aid for Scientific Research on Innovative Areas "Molecular Basis, and Disorders of Control of Appetite and Fat Accumulation" (23126516). The authors are grateful to all participants for their participation in the study and to M. Modest, Steno Diabetes Center, for her excellent technical assistance.

Contribution statement $\mathrm{KH}, \mathrm{PP}, \mathrm{LG}$ and AV designed the study. $\mathrm{KH}, \mathrm{PP}, \mathrm{ST}, \mathrm{EN}, \mathrm{MF}, \mathrm{RR}-\mathrm{M}, \mathrm{LG}, \mathrm{SSL}, \mathrm{JW}$ and AV analysed data and contributed to discussion. KH and JW wrote the manuscript. KH, PP, ST, EN, MF, RR-M, LG, SSL, JW and AV revised the manuscript. All of the authors gave final approval of the version to be published.
Duality of interest S.S. Lund and P. Poulsen have equity stock in Novo Nordisk A/S. P. Poulsen is employed by Novo Nordisk A/S. The remaining authors declare that there is no duality of interest associated with this manuscript.

\section{References}

1. Kawano K, Hirashima T, Mori S, Saitoh Y, Kurosumi M, Natori T (1992) Spontaneous long-term hyperglycemic rat with diabetic complications. Otsuka Long-Evans Tokushima Fatty (OLETF) strain. Diabetes 41:1422-1428

2. Hida K, Wada J, Eguchi J et al (2005) Visceral adipose tissue-derived serine protease inhibitor: a unique insulin-sensitizing adipocytokine in obesity. Proc Natl Acad Sci U S A 102:10610-10615

3. Youn BS, Klöting N, Kratzsch J et al (2008) Serum vaspin concentrations in human obesity and type 2 diabetes. Diabetes $57: 372-377$

4. Seeger J, Ziegelmeier M, Bachmann A et al (2008) Serum levels of the adipokine vaspin in relation to metabolic and renal parameters. J Clin Endocrinol Metab 93:247-251

5. Gulcelik NE, Karakaya J, Gedik A, Usman A, Gurlek A (2009) Serum vaspin levels in type 2 diabetic women in relation to microvascular complications. Eur J Endocrinol 160:65-70

6. von Loeffelholz C, Möhlig M, Arafat AM et al (2010) Circulating vaspin is unrelated to insulin sensitivity in a cohort of nondiabetic humans. Eur J Endocrinol 162:507-513

7. Poulsen P, Grunnet LG, Pilgaard K et al (2009) Increased risk of type 2 diabetes in elderly twins. Diabetes 58:1350-1355 